\title{
ESPAÇO, VÍDEO E ATIVISMO NO TRABALHO VISUAL DE DAVID WOJNAROWICZ
}

\author{
SPACE, VIDEO AND ACTIVISM IN DAVID WOJNAROWICZ'S VISUAL WORK
}

César de Siqueira Castanha*

\section{Resumo}

Este artigo busca compreender como opera uma iniciativa ativista e política no trabalho visual de David Wojnarowicz (1954-1992), identificado como um dos artistas visuais envolvidos com a luta pelo reconhecimento do HIV e assistência à população soropositiva, a partir de uma relação desse trabalho com a materialidade do espaço e a busca por uma espacialidade alternativa para produção e o consumo da arte. Para isso, primeiro, o artigo investiga uma inquietação contra o espaço institucional da arte, considerando uma reincidência histórica dessa reivindicação. Depois, buscase analisar o trabalho visual - e, principalmente, videográfico - de Wojnarowicz a partir de contextos histórica e geograficamente específicos de ansiedade política e de uma iniciativa de reconfiguração do espaço comum a que estão vinculados.

Palavras-chave: Artes visuais. Espaço. Ativismo. Vídeo. David Wojnarowicz.

\section{Abstract}

This article seeks to understand how an activist and political initiative operates in the visual work of David Wojnarowicz (1954-1992), identified as one of the visual artists involved in the struggle for the recognition of HIV and assistance to the seropositive population, based on a relation of this work with the materiality of space and the search for an alternative spatiality for the production and consumption of art. To accomplish this understanding, first, the article investigates an uneasiness against the institutional space of art, considering a historical repetition of this claim. Afterwards, we seek to analyze Wojnarowicz's visual and, mainly, videographic work from historical and geographically specific contexts of political anxiety and its initiative to reconfigure the common space.

Keywords: Visual arts. Space. Activism. Video. David Wojnarowicz.

\section{Datas de submissão e aprovação do artigo}

Submissão: $15 / 8 / 2018$

Aceito: $19 / 8 / 2020$

\footnotetext{
* Professor substituto do Departamento de Comunicação Social da Universidade Federal de Sergipe (DCOS/UFS). Doutorando do Programa de Pós-Graduação em Comunicação da Universidade Federal de Pernambuco (PPGCOM/CAC-UFPE). E-mail: cesars.castanha@gmail.com
} 


\section{INTRODUÇÃO}

No final de 2010, a obra A fire in my belly (1990), um trabalho em vídeo do artista nova-yorkino David Wojnarowicz (1954-1992) foi retirado da exposição "Hide/seek: difference and desire in American portraiture", na National Portrait Gallery, um dos museus do instituto smithsoniano, na cidade de Washington (CARR, 2012). O motivo para isso foi a sequência, considerada ofensiva - o então presidente da Liga Católica, Bill Donohue, definiu a imagem como "discurso de ódio" (CARR, 2012) - em que se apresenta um conjunto de formigas subindo por um crucifixo.

$\mathrm{Na}$ biografia do artista escrita por Cynthia Carr, intitulada Fire in the belly: the life and times of David Wojnarowicz, a autora, já na introdução do livro, propõe a seguinte contra-interpretação para a sequência do vídeo:

Mesmo quando ele confrontava o poder, David nunca viu seu trabalho como uma provocação. Ele o via como uma maneira de falar a sua verdade, um maneira de desafiar ou ao menos iluminar o que muitos aceitam como dado. Isso que as formigas representam para ele humanidade avançando em frente, despreocupada com o que jaz sob seus pequenos pés, indiferente às estruturas que a cercam (CARR, 2012. Tradução nossa ${ }^{1}$ ).

Figura 1: Formigas sobre um crucifixo em imagem de ITSOFOMO (1989)

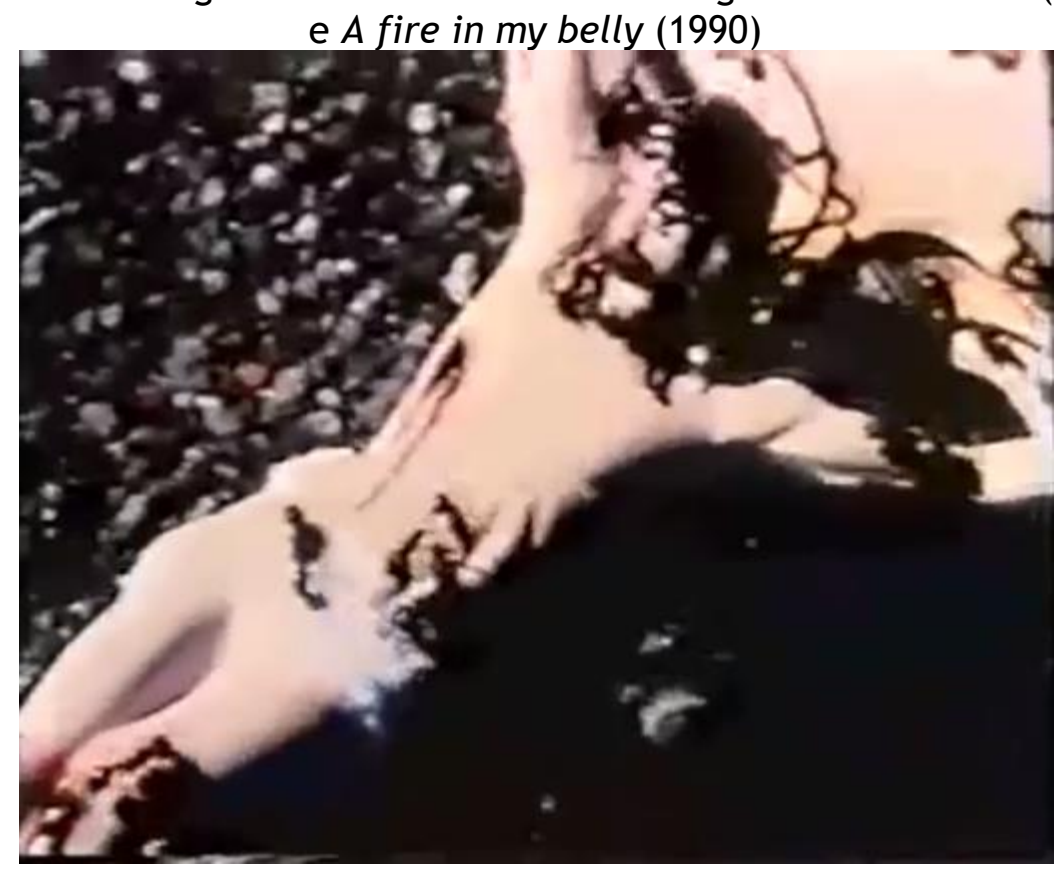

Fonte: print screen do vídeo A fire in my belly

\footnotetext{
${ }^{1}$ No original: "Even when he aggravated the powerful, David never saw his work as provocation. He saw it as a way to speak his truth, a way to challenge or at least to illuminate what many accept as given. That's what the ants actually represented to him-humanity rushing along heedless of what lies under its tiny feet, indifferent to the structures that surround it".
} 
Não fica claro se essa leitura para a imagem surgiu, como a maior parte do livro, das entrevistas com Wojnarowicz e pessoas próximas a ele conduzidas por Carr ou se é algo que a autora mesma deduz das intenções do artista. Wojnarowicz é, afinal, um dos artistas vinculados à organização de arte contemporânea Visual Aids, que foi fundada em 1988 com o compromisso de promover o reconhecimento da Aids e criar diálogo acerca de questões ligadas ao $\mathrm{HIV}^{2}$. Na página da organização dedicada a apresentar o artista e seu trabalho, afirma-se que "no fim dos anos 1980, depois de ser diagnosticado com Aids, a arte de Wojnarowicz tomou uma afiada perspectiva política"3.

É possível que isso se refira a trabalhos como ITSOFOMO (in the shadow of forward motion) (1989) e A fire in my belly (1990). O primeiro, uma performance com vídeo, envolve um texto relativo à experiência da doença; e o segundo, objeto da já mencionada controvérsia, reutiliza muito do material em vídeo que compõe o trabalho anterior (embora, nesse caso, não haja a participação do texto).

Carr e a Visual Aids, ao defender o trabalho de Wojnarowicz, e o grupo conservador representado por Bill Donohue, ao se opor a ele, todos oferecem contextos para a apreensão de um discurso desses trabalhos. Este artigo não pretende se contrapor a essa disputa pela apreensão de um discurso. Entendo, inclusive, como defenderei adiante, que as imagens de Wojnarowicz passam por uma ansiedade por significar. Ao descrever uma nova disposição do artista, prestes a voltar de uma longa viagem a Paris e a assumir uma posição como artista visual na cena nova-yorkina, Carr descreve: "tudo que ele olhava eram sinais e portentos. Tudo foi ampliado agora. Tudo significava" (2012).

O objetivo deste artigo é entender como a iniciativa ativista opera no trabalho visual de Wojnarowicz, para além do possível discurso que pode ser apreendido de suas obras. Para isso, questiono como esse trabalho reivindica uma participação em espaços fora das instituições artísticas e uma reconfiguração desses espaços. $\mathrm{E}$, em um último momento, a partir de uma breve análise da obra ITSOFOMO: in the shadow of forward motion (1989), como o vídeo atende a essa iniciativa ativista e contribui com a reconfiguração de um espaço comum.

Antes de se aproximar das artes visuais, quando ainda trabalhava quase exclusivamente com poesia, Wojnarowicz, respondendo a um questionário montado por sua própria mãe, descreveu seu processo criativo como "um filme mental", "um composto de imagens visuais e emocionais" (citado por CARR, 2012). A pergunta que inspirou essa resposta fora: "Você tem uma mensagem para transmitir através da sua poesia?". Não quero utilizar essa resposta, uma passagem tão desinteressada de um Wojnarowicz ainda muito jovem, como uma dura evidência para as intenções do artista. Mas ainda assim acho curioso como ele recusa a ideia de uma mensagem, um discurso contido em sua poesia, e propõe no lugar disso a imagem de um filme, "um composto de imagens visuais e emocionais". É essa alternativa, específica ao vídeo, que neste artigo busco compreender como opera.

\footnotetext{
2 Disponível em: <https://www.visualaids.org/about>. Data de acesso: 15 de agosto de 2018.

3Disponível em: <https://www.visualaids.org/artists/detail/david-wojnarowicz>. Data de acesso: 15 de agosto de 2018.
} 


\section{ESPECIFICIDADES HISTÓRICAS}

Há uma pasta no meu computador nomeada "ITSOFOMO (in the shadow of forward motion)". Dentro dela, encontro excertos em vídeo da performance que levou esse título: uma parceria entre David Wojnarowicz e o músico Ben Neill, apresentada em 1989 no The Kitchen, em Nova York. Segundo Jennifer Doyle, professora da Universidade da Califórnia, "em sua encarnação original ITSOFOMO era uma performance ao vivo. Wojnarowicz lia seu trabalho acompanhado por projeções em multicanais de seu filme enquanto Ben Neill apresentava uma trilha original em seu mutantrumpet"' (DOYLE, 2013).

Tenho acesso a vestígios dessa performance: um vídeo editado para juntar, em uma mesma unidade material, imagens, texto e trilha sonora. 0 que nos resta é, de fato, um excerto do ITSOFOMO. Há um anacronismo inerente na nossa relação com esse trabalho. Se Philippe Dubois, nas palavras do pesquisador Arlindo Machado, "sugere pensar o vídeo como um estado e não como um produto" (2004, p. 13), o que isso diz de uma relação com esse material que se dá, em grande parte, a partir de plataformas digitais, de excertos, versões e cortes disponibilizados em canais como o YouTube?

Trabalhamos com esses vestígios, com as semelhanças que eles carregam em relação ao material original, como uma lembrança da sua textura ou a sua profundidade específica ${ }^{5}$. Mas acessamos esse material como unidades homogêneas, o que nos distancia ainda mais da materialidade do vídeo, da performance e da cenografia envolvidas na experiência do vídeo. Philippe Dubois, na introdução do livro Cinema, vídeo, Godard, reconhece a si mesmo e ao vídeo como parte de uma geração intermediária, entre o cinema e a informática, "como um ser de passagem, dotado de existência breve e identidade incerta - que são sua força: forma opaca e dupla, intermediária, natureza mista de fenômeno transitório" (2004, p. 21).

Evidentemente, no campo da arte experimental ou vanguardista, a historicidade não é exclusiva ao vídeo ou à videoarte. Na epígrafe de $A$ history of experimental film and video, o autor A. L. Rees resgata a afirmação de Clement Greenberg de que não se define vanguarda, mas "se reconhece como um fenômeno histórico" (1968 citado por REES, 2011, p. x). Esse entendimento é levado adiante por Rees, que, no mesmo livro, esforça-se para apresentar cada um de um conjunto de movimentos artísticos a partir de especificidades históricas e geográficas.

No caso do trabalho de David Wojnarowicz, a especificidade histórica do vídeo não é a única que deve ser levada em consideração. Como já foi dito, em 1989, Wojnarowicz apresentou ITSOFOMO no The Kitchen, um espaço sem fins lucrativos fundado em 1971 dedicado à apresentação e ao compartilhamento de arte experimental que já recebeu artistas como Laurie Anderson, Robert Mapplethorpe e Cindy Sherman 6 . 0 The Kitchen não era o único espaço em Nova York compartilhado por uma sequência de gerações de artistas experimentais. No fim de 1979, um grupo

\footnotetext{
${ }^{4}$ Nas palavras de Ben Neill, o mutantrumpet é um instrumento híbrido elétro-acústico criado por ele nos anos 1980. Essa apresentação e uma demonstração do instrumento estão disponíveis em <https: //www. youtube.com/watch?v=umBVBu6nFbl>.

5 Segundo Arlindo Machado, "a profundidade sugerida pelo vídeo é, por assim dizer, uma profundidade de superfícies, fundada na estratificação da imagem em camadas, engendrando portanto um efeito de relevo que só pode existir na imagem, não no mundo designado por ela" (2004, p.14).

${ }^{6}$ Disponível em: <http://thekitchen.org/about>. Data de acesso: 15 de agosto de 2018.
} 
de 35 artistas ocuparam um prédio abandonado no Lower East Side, no sudestede Manhattan, e montaram a exposição Real Estate Show (CARR, 2013). A ocupação durou poucos dias, mas:

a ideia de que isso havia acontecido teve mais consequência que qualquer coisa exibida. A prefeitura respondeu à invasão e à agitação que a acompanhou cedendo aos artistas outro prédio nas proximidades, na Rivington Street. Ele se tornou o ABC No Rio, seu nome tirado de um fragmento de uma sinalização do outro lado da rua. No Rio não apenas precedeu as galerias do East Village, como sobreviveu a elas (CARR, 2013. Tradução nossa ${ }^{7}$ ).

Em uma carta para a revista de arquitetura Skyline, Peter Fend, que participara do Real Estate Show, afirma que os artistas, no Lower East Side, "pretendem permanecer e ajudar a determinar a evolução da área" (FEND, 1980, p. 59 citado por CARR, 2012). Em julho de 1980, a exposição Times Square Show abria num "antigo depósito de ônibus entre a 41th Street e a Sétima Avenida com por volta de uma centena de artistas, incluindo Jean-Michel Basquiat, Keith Haring, Jenny Holzer e Kenny Scharf” (CARR, 2012). Para Carr, o sucesso da exibição "provou o quão cansado todo mundo tinha ficado com paredes lisas brancas e pinturas formalistas penduradas nelas" (2012). Numa crítica publicada na revista Art in America, Jeffrey Deitch elogiou a exibição como uma "expressão ou comunicação sexual e divertida de mensagens políticas" e reconheceu o erro que seria tê-la em um espaço limpo (1980, p. 12 citado por CARR, 2012). Esse entendimento de uma outra espacialidade possível para a arte é reconhecido por Carr como central para a geração de artistas que ocuparia o East Village.

Parecem-me evidentes as implicações formais de uma tomada de posição como essa. Uma espacialidade alternativa para a exibição e consumo de arte poderia se revelar interessante ao trabalho, por exemplo, com o vídeo, sendo ele mesmo a configuração de uma espacialidade alternativa à produção e consumo da imagem em movimento - já que, nas palavras de Arlindo Machado, "o vídeo pode ser também um dispositivo: um evento, uma instalação, uma complexa cenografia de telas, objetos e carpintaria" (2004, p. 13). O reconhecimento já mencionado do vídeo como um estado, mais que um produto, converge com a iniciativa de pensar a arte no que Carr se refere como um anti-space - uma expressão talvez inadequada para o que, acredito, é na verdade uma veemente afirmação de espacialidade -, a ocupação de um espaço comum, marcado pela efemeridade e inconstância.

O vídeo, é claro, não é a única mídia a se relacionar com essa reivindicação de espacialidade. Quando fez parte da banda 3 Teens Kill 4, David Wojnarowicz identificava seu papel no conjunto como "gravador de fita", referindo-se às gravações sonoras que ele trazia do trânsito, de conversas da rua ou do rádio que eram adicionadas às músicas da banda (CARR, 2012). A banda também costumava se apresentar com guitarras desafinadas, instrumentos de baixa qualidade, serrando um violino de apenas uma corda (CARR, 2012). Entrevistado por Carr, Doug Bressler, que

\footnotetext{
${ }^{7}$ No original: "the idea that it had happened was much more consequential than anything exhibited. The city responded to the break-in and attendant agitprop by giving the artists another building on nearby Rivington Street. It became $A B C$ No Rio, its name lifted from a sign fragment across the street. No Rio not only preceded the East Village galleries but also outlasted them".
} 
se juntou ao 3 Teens Kill 4 como guitarrista em 1981, admite uma preocupação com a possibilidade de ter "arruinado a banda" ao estilizar a música (2012).

Percebe-se a continuidade de uma recusa, como nas ocupações do Real Estate Show e do Times Square Show, de se ser integrado a espaços da arte. Essa recusa não é de modo algum exclusiva aos artistas de Manhattan ou a essa geração específica (embora ela se apresente sempre a partir de especificidades históricas). Em 1971, a revista Art News publicou o texto A Educação do Não Artista, parte 1, de Allan Kaprow, que discute o apelo (conceitual ou de determinados movimentos de arte experimental) para um reconhecimento artístico de diversas materialidades tecnológicas (por exemplo, o módulo de pouso na lua), históricas ("o teatro da guerra no Vietnã") e espaciais (a arquitetura dos postos de gasolina) que escapam a instituições de arte (1993, p. 97). Para Kaprow, os artistas interessados nesse paradoxo "desejam prolongar sua resolução, mesmo que por uma semana ou duas" (1993, p. 98). Diz o autor:

Os proponentes da não arte, de acordo com essa descrição, são aqueles que, consistentemente ou uma vez ou outra, escolheram trabalhar fora da palidez dos estabelecimentos de arte - quer dizer, em suas cabeças ou em seu domínio natural diário. Todas as vezes, porém, eles informaram o meio artístico estabelecido de suas atividades, para colocar em movimento as incertezas sem as quais seus atos não teriam significado. A dialética arte/não-arte é essencial (KAPROW, 1993, p. 98 e 99. Tradução nossa ${ }^{8}$ ).

No seu Teoria da vanguarda, Peter Bürger entende "a exigência de que a arte volte a ser prática", referindo-se ao "funcionamento da arte na sociedade" (1993, p. 90), como uma reivindicação vanguardista - e um fracasso neo-vanguardista. Para o autor, uma provocação como o ready-made de Duchamp, seu urinol assinado, é parte de uma crítica de circunstâncias históricas. Escrevendo sobre a continuidade de provocações semelhantes, que se utilizam da dialética entre arte e não-arte para depois retornar ao meio artístico ou ao menos informá-lo, ele coloca que "quando o protesto da vanguarda histórica contra a instituição arte chega a considerar-se como arte, a atitude de protesto da neo-vanguarda tem que ser falsa” (1993, p. 95).

Não me parece, no entanto, que a rejeição ao espaço hegemônico da arte no caso dos artistas do East Village seja uma que busque o caminho de volta para a legitimação institucional. Bürger não antecipa, ou leva em consideração, movimentos artísticos organizados que sustentam a ambição de reunião da arte à praxis vital e estão de fato alheios aos espaços dos museus e pouco interessados em disputar conceitualizações para o que é ou não é arte. A falta de registro das intervenções urbanas e dos objetos artísticos que circularam por aquele espaço demonstra o desengajamento desses artistas à arte institucionalizada, ainda que repetissem aquilo que Kaprow se refere como "formatos sagrados transmitidos por sua tradição", como exposições e colunas de cultura na mídia de massas (1993, p. 101).

\footnotetext{
${ }^{8}$ No original: “Nonart's advocates, according to this description, are those who consistently, or at one time or other, have chosen to operate outside the pale of art establishments - that is, in their heads or in the daily or natural domain. At all times, however, they have informed the art establishment of their activities, to set into motion the uncertainties without which their acts would have no meaning. The art-non-art dialectic is essential".
} 
Isso só acentua, é claro, a especificidade histórica e espacial do que acontecia no East Village na década de 1980. A ideia de vanguarda dificilmente dá conta de uma política das iniciativas artísticas que participaram desse movimento. Não posso aqui, tampouco, oferecer uma resolução para a pluralidade estética do trabalho desses artistas, tratando-os por uma unidade que não caracteriza a diversidade do que foi produzido. Apego-me ao caso de David Wojnarowicz e seu próprio engajamento ativista, sua particular recusa de participar dos espaços institucionais, reconhecendo sempre a materialidade de seu trabalho a partir de suas especificidades históricas e geográficas.

\section{DAVID WOJNAROWICZ QUER MUDAR O MUNDO}

Por que é tão importante, para mim, tratar o trabalho de David Wojnarowicz a partir dessas especificidades? Primeiro, porque vejo a materialidade do seu trabalho com vídeo como indissociável dessa especificidade e sinto a necessidade de expor a minha relação anacrônica com esse trabalho - um anacronismo que pode ser resumido simplesmente à falta de acesso à mise-en-scène original de obras como ITSOFOMO e A fire in my belly. Depois, porque, tomando uma posição mais pessoal diante do trabalho de Wojnarowicz, entendo-o como indissociável do engajamento ativista do artista - um engajamento que, evidentemente, precisa ser informado a partir dessas especificidades.

Procuro recorrer a seu ativismo não para oferecer interpretações de seu discurso, mas para reconhecer um gesto de militância na materialidade mesma do seu trabalho. Wojnarowicz pode se dizer ansioso por significar e investir, nas suas imagens, numa expectativa pelo trabalho metafórico. Mas não é o significado final dessas imagens que ele leva adiante em suas obras, mas sim a possibilidade de significar das suas imagens e a não apreensão de um significado único e final. Cynthia Carr e Bill Donohue podem disputar o significado do crucifixo coberto por formigas, mas o que temos ali ainda é simplesmente a imagem de um crucifixo coberto por formigas, compreensível a qualquer pessoa familiarizada com os dois objetos.

O vídeo, como já foi sugerido, possibilita o "composto de imagens visuais e emocionais" que participam do processo criativo de Wojnarowicz. Mas como envolver esse composto de imagens em sua iniciativa militante? Como fazê-las, usando as palavras do artista, "seduzir pessoas, fazê-las se sentirem tranquilas e ainda fazêlas renunciar a todas as coisas terríveis da Terra" (CARR, 2012)? Wojnarowicz se interessava pelo graffiti de Jean-Michel Basquiat e os desenhos de Keith Haring (CARR, 2012), dois artistas que trabalharam a partir de intervenções no espaço visual urbano. Wojnarowicz também trabalhou com estêncil, técnica de reprodução figurativa, utilizando-se de "símbolos internacionais" (CARR, 2012), como uma casa em chamas e um homem em queda. 
Figuras 2 e 3: À esquerda, estêncil de David Wojnarowicz; à direita, fotografia do projeto Arthur Rimbaud in New York (1978-79)
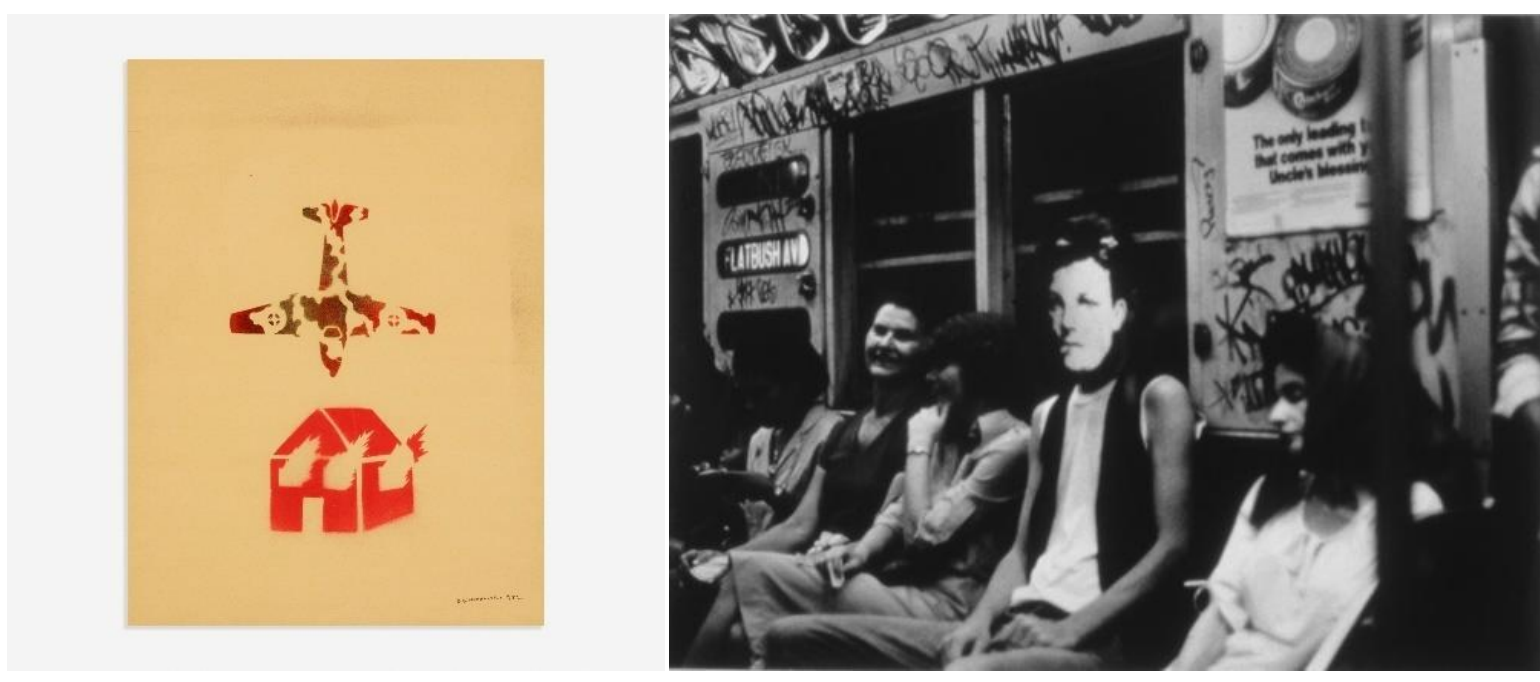

Fontes: Wright Auctions e Museo Reina Sofia

Wojnarowicz, no entanto, não reconheceu seu trabalho com estêncil como um gesto político efetivo, afirmando que havia sido uma tentativa de entrar no mundo da arte, o que mais tarde ele entendeu como uma impossibilidade (CARR, 2012). Ainda assim, o estêncil é uma continuidade do exercício de intervenções no espaço urbano, que interessava Wojnarowicz desde a utilização dos sons da cidade na banda 3 Teen Kill $4^{9}$ até o princípio de seu trabalho fotográfico, quando acompanhou seus amigos caminhando pela cidade de Nova York utilizando máscaras com o rosto do poeta Arthur Rimbaud.

0 vídeo acompanha o desenvolvimento dessas atividades no espaço urbano. As imagens em ITSOFOMO e $A$ fire in my belly são, como no estêncil, universais. $O$ apelo ativista não está no discurso ou mesmo na metáfora, mas em reconfigurar o espaçocomum com essas imagens. Do mesmo modo, a recusa a participar dos espaços da arte institucional não funciona como uma negociação com esse espaço, mas como uma ação em outros espaços. Essa iniciativa ativista recorre, assim, à política da arte nos termos do que anos depois seria defendido por Jacques Rancière, para quem a arte:

é política antes de mais nada pela maneira como configura um sensorium espaço-temporal que determina maneiras do estar junto ou separado, fora ou dentro, face a ou no meio de... Ela é política enquanto recorta um determinado espaço ou um determinado tempo, enquanto os objetos com os quais ela povoa este espaço ou o ritmo que ela confere a esse tempo determinam uma forma de experiência específica, em conformidade ou em ruptura com outras: uma forma específica de visibilidade, uma modificação das relações entre formas sensíveis e regimes de significação, velocidades específicas, mas também e antes de mais nada formas de reunião ou de solidão. Porque a política, bem antes de ser o exercício de um poder ou uma

\footnotetext{
9 Faixa da banda 3 Teens Kill 4 disponível em: <https://www.youtube.com/watch?v=PkVY9zRkpJ8>. Data de acesso: 15 de agosto de 2018 .
} 
luta pelo poder, é o recorte de um espaço específico de "ocupações comuns"; é o conflito para determinar os objetos que fazem ou não parte dessas ocupações, os sujeitos que participam ou não delas, etc. Se a arte é política, ela o é enquanto os espaços e os tempos que ela recorta e as formas de ocupação desses tempos e espaços que ela determina interferem com o recorte dos espaços e dos tempos, dos sujeitos e dos objetos, do privado e do público, das competências e das incompetências, que define uma comunidade política (RANCIÈRE, 2010, p. 46)

Rancière aqui se refere ao que ele defende como a política da arte no regime estético de identificação da arte. Constituindo-se na virada do século XVIII para o XIX, o regime estético é determinado por uma igualdade indiferente dos objetos ao olhar dos sujeitos. Para o autor, "o lugar solitário proposto à meditação de um eu qualquer no nós dos subúrbios deserdados é claramente um herdeiro desse espaço paradigmático da estética" (2010, p. 47). Isso não significa ignorar condições de produção e privilégios de distribuição da arte, mas reconhecer um paradoxo vinculado à própria identificação da arte.

Esse paradoxo me parece algo bastante reconhecido e presente na inquietação dos movimentos de vanguarda e neo-vanguarda em reconfigurar ou confrontar as fronteiras da arte como instituição. Se, tomando pela crítica de Bürguer e Kaprow, os movimentos de vanguarda e neo-vanguarda fracassam pela contradição de combater a fronteira enquanto reivindicam o espaço dentro do território que ela protege, as galerias do East Village nos anos 1980 habitam um tipo de pós-fracasso da tentativa de solucionar o paradoxo. Rancière descreve o espaço do regime estético da arte como "um museu esvaziado de toda obra" (2010, p. 47), e talvez seja exatamente isso que os artistas do East Village aceitam e abraçam.

As imagens de Wojnarowicz participam desse espaço de indiferença não apenas no sentido de estar no espaço comum em um regime determinado pela igualdade indiferente, mas também no de reivindicar a indiferença ao se utilizar, no seu trabalho com estêncil e pintura, de imagens e objetos comuns, reconhecíveis ou simplesmente banais. É, no entanto, pelo modo como os objetos são deslocados da sua materialidade, ajustados e reapresentados como imagem que o trabalho de Wojnarowicz se revela politicamente na reconfiguração desse espaço comum.

No ensaio que apresenta a exposição onde Wojnarowicz apresentou um de seus primeiros trabalhos de pintura, Hujar dreaming, em 1981, Susan Putterman escreve que o artista "constrói um universo desprovido de razão moral" e "confronta o espectador com uma visão de anarquia e insanidade" (citada por CARR, 2013). Hujar dreaming é uma pintura criada a partir de uma foto que Wojnarowicz tirou do fotógrafo Peter Hujar, em que Hujar está deitado em uma calçada. Essa fotografia foi utilizada por Wojnarowicz não só para Hujar dreaming, mas também para uma série de outras pinturas, instalações e estêncil. Putterman destaca o modo como Hujar dreaming é pintada "plana e uniformemente" e ainda assim, para ela, "cria um sentido de ansiedade” (citada por CARR, 2012). 
Figura 4: Hujar dreaming (1981), um dos trabalhos feitos a partir de uma fotografia de Peter Hujar

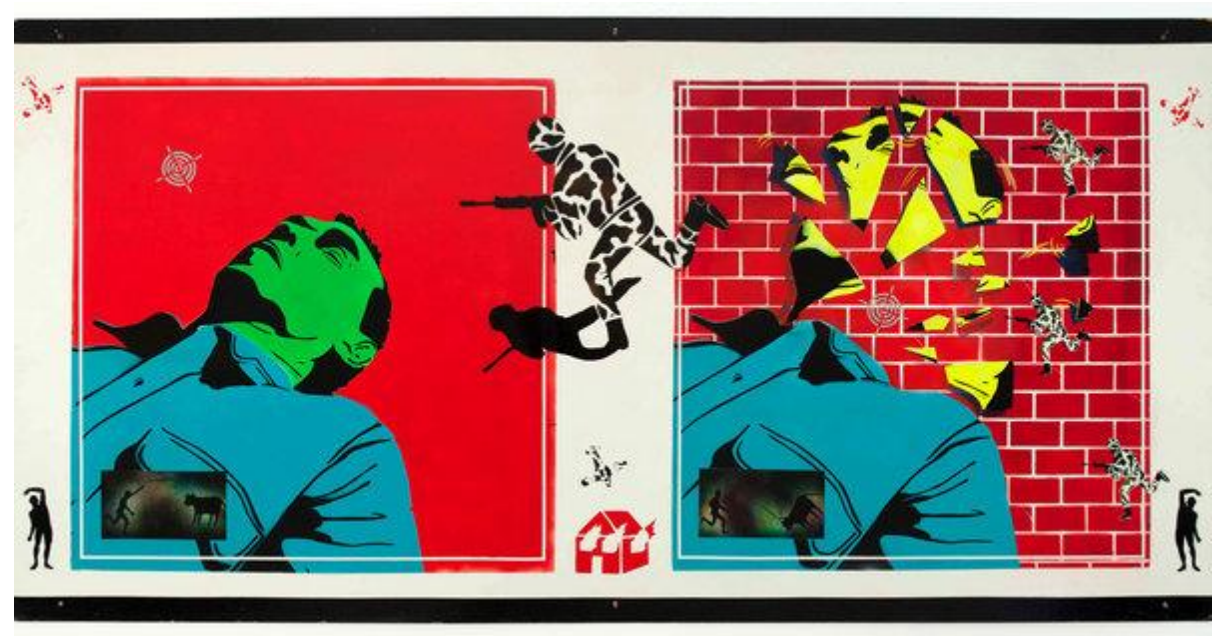

Fonte: Financial Times

Hujar dreaming é um exemplo de como Wojnarowicz se afasta de uma política de representação calcada num referente de realidade, para uma política de reconfiguração do espaço. Se as máscaras com o rosto de Rimbaud eram parte de um trabalho fotográfico que exigia também uma ação performática no espaço urbano, agora a produção do artista participa de uma reconstrução do espaço urbano. Putterman descreve as imagens de Wojnarowicz como "de violência e terrorismo urbano" (citada por CARR, 2012), e talvez "terrorismo urbano" seja um bom modo de descrever essa reconfiguração do espaço e dos seus referentes materiais em imagens planas, bidimensionais e superficiais no sentido literal da palavra.

\section{DAVID WOJNAROWICZ E O VÍDEO}

Seria um paradoxo pensar que uma ação artística e política que age na materialidade do espaço comum o faça a partir de uma desmaterialização desse mesmo espaço comum? No caso de Hujar dreaming e do trabalho com estêncil, ainda que desconfigurem uma materialidade do referente (como a foto de Hujar, que se torna uma pintura plana e uniforme), tratam-se de imagens de uma materialidade evidente, que podem ser tocadas. Ainda assim, a sua superficialidade bidimensional antecipa o trabalho de Wojnarowicz com o vídeo, que tem uma investida militante mais notória.

No texto "Máquinas de imagens: uma questão de linha geral", Dubois descreve o simulacro da televisão como o "desaparecimento de todo o Sujeito e de todo o Objeto", uma relação em que "não há mais Comunhão, só nos resta a Comunicação" (2004, p. 47). O vídeo, para o autor, continua essa imaterialidade como uma "trama eletrônica" e uma "pura operação, sem outra realidade 'objetal' que a materializaria no espaço do visível” (2004, p. 64). O simulacro, num trabalho de vídeo de Wojnarowicz, é levado adiante, à comunhão do espaço comum e, consequentemente, à reconfiguração de sua materialidade. Se Dubois antecipa um 
"triunfo da simulação" com a imagem informática e o advento da realidade virtual (2004, 66), referimo-nos aqui a um movimento que havia antes reivindicado a participação no espaço comum, rejeitado os espaços do museu para se envolver com a materialidade urbana.

Quando Wojnarowicz apresentou ITSOFOMO no The Kitchen em 1989, relacionar-se com a materialidade da cidade já significava algo além de interferências urbanas como o estêncil. No final dos anos 1980, a Aids se tornou a principal causa de morte na cidade de Nova York para homens entre 25 e 44 anos e mulheres negras entre 15 e 44 anos (MUSTO; EPSTEIN, 2010). Em 1987, Peter Hujar, um dos amigos mais próximos de Wojnarowicz, morreu, vítima da epidemia. 0 texto que fez parte da performance ITSOFOMO começa como um relato de alguém que tem um amigo ou companheiro soropositivo no hospital.

Uma performance como ITSOFOMO, no entanto, não se resolve no texto. Ela envolve também uma montagem (imagética e sonora) e uma cenografia a que, como já foi dito, não tenho acesso. A relação do texto com as imagens é de um fluxo descontínuo de pensamento. Não se trata do experimento com a materialidade da mídia de artistas como Nam June Paik. Mas é ainda a "imagem-ato" e a "imagem como olhar ou o olhar como imagem" que Dubois descreve como o paradoxo da representação do vídeo, em que $\mathrm{o}$ ato de produção e o objeto que resulta desse ato são designados pela mesma palavra (2004, p. 72).

0 que Wojnarowicz faz, além de montar as imagens como um ensaio intermitente, como talvez ele mais enfaticamente utiliza a especificidade do vídeo, é o modo como reclama a superficialidade das imagens. Desde a pintura, as montagens fotográficas e o estêncil, Wojnarowicz trabalha as diferentes mídias como um simulacro, mas um simulacro a participar ativamente do espaço urbano e das questões que tomam esse espaço urbano. Sua iniciativa ativista é uma que propõe essa ambiguidade de uma ação no espaço a partir de uma desconfiguração desse espaço.

Mesmo que Wojnarowicz não se utilize de técnicas de mixagem de imagens como a incrustação ou a justaposição - e sua utilização de transparência seja mínima -, técnicas que fazem com que a imagem do vídeo seja proveniente de fontes diversas, suas imagens ainda se distanciam da contiguidade espacial efetiva dos dados que estão representados nela, assim como Hujar dreaming se afastava da realidade da matéria da foto de Hujar. Por um lado, parte das imagens de ITSOFOMO não têm referencial direto. São imagens de arquivo incorporadas, como imagens produzidas como simulação de fenômenos espaciais que ele filma de um livro de fotografias (um vídeo da impressão da imagem da simulação) e vídeos de imagens transmitidas por uma tela de televisão. Ou, em outros casos, imagens deslocadas de seu referente ao ponto de se tornarem indistinguíveis ou reconhecíveis apenas como imagens e não como objetos. 
Figuras 5 e 6: Imagens de ITSOFOMO (1989)

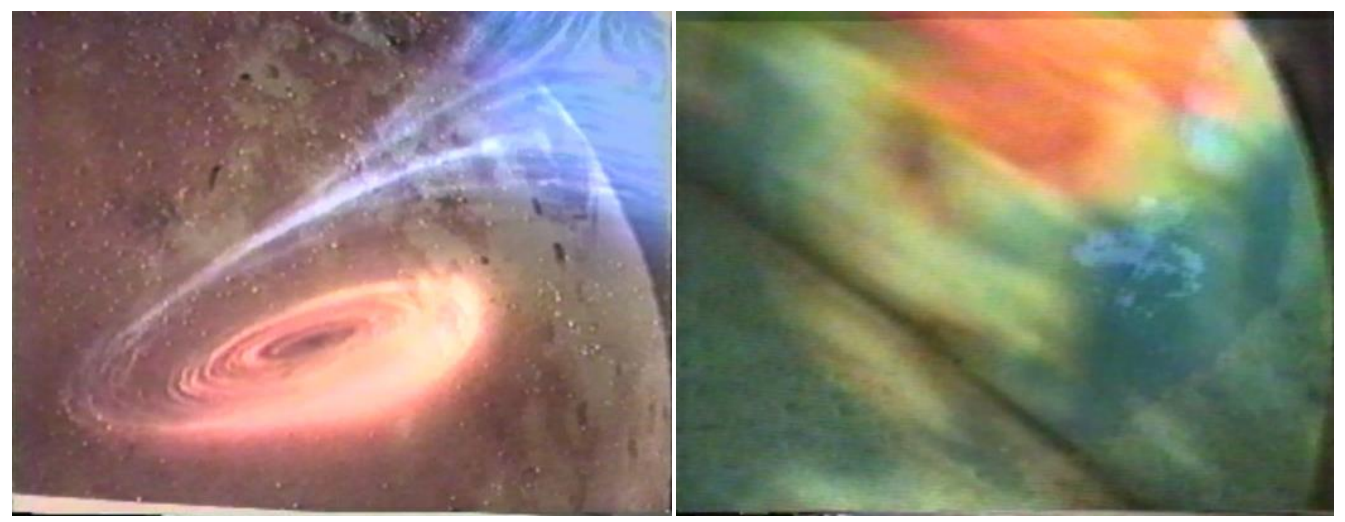

Fonte: print screens do vídeo

O texto que acompanha as imagens de ITSOFOMO, por outro lado, tem uma abordagem direta e clara da marginalização e do sofrimento causados pela relação omissa da sociedade com a epidemia. Isso não implica que as imagens sejam desprovidas desse discurso ou alienadas de qualquer significado. Já apresentei, no início deste artigo, uma leitura interpretativa para imagens que estão também nessa obra. Essa leitura não deixa de ser justificada. O que pretendo é chamar atenção para uma outra política de ITSOFOMO, uma que se pauta pelo deslocamento do senso comum e reconfiguração do espaço e tempo. Uma que se dá, no caso deste trabalho, pela utilização do vídeo, por trazer o simulacro à materialidade do espaço.

Enfim, uma política do vídeo. As especificidades da mídia, principalmente no modo como ela é utilizada por vídeo-artistas, afastam as suas imagens de um referente fora de campo. Dubois reafirma essa perda de referente quando opõe a espessura da imagem do vídeo à profundidade de campo do cinema. Para o autor, o vídeo produz uma profundidade de outra ordem, algo como uma "profundidade de superfícies", em que o artifício de construção (principalmente em trabalhos que se utilizam das técnicas de mixagem de imagens) "não corresponde a nenhuma realidade física" (2004, p. 87). No regime videográfico, portanto:

Estamos em um universo que absorve e regurgita tudo, estamos em um mundo sem limite, e portanto sem espaço off, já que ele contém em si mesmo (em sua matéria de imagem, em seu próprio corpo interior) a totalidade do universo. A imagem totalizante ou o espaço off incorporado (DUBOIS, 2004, p. 94).

\section{MUNDO, MUDADO}

No texto Fear of mice, referindo-se ao redesenvolvimento do centro de Manhattan conduzido nos anos 1990 por Robert Stern, o autor Andreas Huyssen menciona o aspecto inusitado de o planejamento para aquela área, no lugar de transformá-la em um espaço empresarial, reconhecê-la como "centro dos teatros, entretenimento e cultura da publicidade", concluindo: "Isso é algo para se construir sobre. Isso é quase já tradicional” (HUYSSEN, 2003, p. 87). A Times Square que surge depois redesenvolvimento urbano fez da presença da imagem digital - e, 
especialmente, publicitária - na materialidade urbana um ponto turístico. E, como é de se esperar de um ponto turístico, esse espaço surge, para repetir as palavras de Huyssen, "quase já tradicional".

O texto de Huyssen se dirige à rejeição à "disneyficação" da Times Square (como o processo ficou popularmente conhecido) como uma nostalgia da esquerda e apatia pela cultura midiática de massa - e por isso o título Fear of mice (medo do rato). $\mathrm{O}$ autor responde a essa apatia mencionando um posicionamento de Walter Benjamin sobre "como a mídia moderna pode radicalmente alterar modos de percepção do mundo, como elas podem explodir percepções fixas de tempo e espaço" (HUYSSEN, 2003, p. 88).

Como Peter Fend prometera na já mencionada carta para a revista Skyline, os artistas do East Village de fato ajudaram a determinar a "evolução da área". Um total de 176 galerias foram abertas na vizinhança (KIRWIN, 1999 citado por CARR, 2012). Essa tendência foi endossada por proprietários, que ofereciam antigas bodegas, clubes sociais e às vezes apartamentos a preços mais baixos de aluguel, o que não duraria muito tempo: o sucesso da iniciativa artística, afinal, aumentaria o valor de propriedade (CARR, 2012). Em 1984, um artigo de Carlo McCormick e Walter Robinson na Art in America se referiria ao East Village como "um conceito de marketing" e "um cenário vanguardista aventureiro de considerável prestígio" (MCCORMICK; ROBINSON, 1984, p. 40 citados por CARR, 2012). Carr comenta as observações feitas pelo artigo:

Eu achei essa declaração chocante, mas eles estavam também nomeando algo real. Ônibus turísticos logo chegariam para mostrar aos curiosos-mas-tímidos o que os artistas forjaram em meio aos escombros (...) Então, duas páginas foram dadas a Craig Owen para sua resposta: "O problema com o puerilismo". Na visão de Owen, o East Village era "um desenvolvimento econômico, mais que estético". Mas alguém tinha assumido outra coisa? Ele rebaixou a apropriação de "produções subculturais" (graffiti, caricaturas). Isso era um problema do East Village? Ele criticou a cena como um "simulacro" da boêmia. Mas parecia real para mim (CARR, 2012. Tradução nossa ${ }^{10}$ ).

A utopia de um outro espaço para a arte, ou para a participação da arte no espaço comum, é superada por essa iniciativa fora da arte - ou daquilo que se reivindica antes de tudo como arte. A política do vídeo tem uma continuidade nos dispositivos da imagem publicitária. Interação, mixagem, superficialidade e a ideia de uma imagem totalizante, sem referente fora da imagem, ressoam como utensílios da publicidade. A reconfiguração do espaço comum produzida pelas telas da Time Square hoje podem reafirmar o vídeo como esse estado transitório, uma experiência mínima entre a imagem cinematográfica e a imagem informática.

\footnotetext{
10 No original: "I found this statement shocking, but they were also naming something real. Tour buses would soon arrive to show the curious-but-timid what the artists had wrought amid the rubble (...) Then, two pages went to Craig Owens for his retort: 'The Problem with Puerilism.' In Owens's view, the East Village was 'an economic, rather than esthetic, development.' But had anyone pretended otherwise? He decried the appropriation of 'subcultural productions' (graffiti, cartooning). Was this an East Village problem? He criticized the scene as a 'simulacrum' of bohemia. But it felt real to me”.
} 


\section{CONSIDERAÇÕES FINAIS}

A ambiguidade produzida pelo vídeo - do simulacro instalado, materializado no espaço comum - no entanto, permanece. Neste artigo, recorri ao trabalho de Wojnarowicz para me dirigir a um potencial político do reconhecimento dessa ambiguidade e à utilização dessa ambiguidade por uma perspectiva ativista. 0 vídeo de Wojnarowicz ou, em uma concepção mais ampla, suas imagens planas e superficiais de "terrorismo urbano" (como Susan Putterman as identifica), produzem uma alternativa à política ativista da comunicação e expectativa de apreensão de um discurso.

Essa alternativa me toca como perfeitamente pertinente ao compartilhamento de um espaço comum, a estar presente no espaço comum, diante de sua produção midiática (telas, outdoors, pichações) e diante do outro e suas pautas. Isso, é claro, não é algo exclusivo de espaços da arte (dentro ou fora dos museus) ou do ativismo. Mas Wojnarowicz recorre aos dois a partir dessa ambiguidade. $\mathrm{E}$ o vídeo, se é "uma forma que pensa não tanto o mundo quanto as imagens do mundo e os dispositivos que as acompanham" (DUBOIS, 2004, p. 100), é também uma forma que pensa a mídia e a espacialidade da mídia.

Seria provavelmente arrogante supor que as imagens digitais das telas da Times Square não dão continuidade ao reconhecimento dessa ambiguidade, ao pensamento da relação da mídia com o espaço. Mas é uma outra configuração do espaço comum que é disputada nesse caso, parte de outras especificidades ideológicas e históricas.

Como uma "imagem-presença, bem mais que uma imagem representação" (DUBOIS, 2004, p. 106), uma política do vídeo implicaria menos na apreensão de um discurso e mais nessa reconfiguração do sensível. Curiosamente, Wojnarowicz escolhe atrelar o vídeo ao relato, ou seja, o simulacro sem referente ao discurso militante. ITSOFOMO é o produto dessas ambiguidades, do virtual levado ao espaço comum e do significado confrontado com a impossibilidade de significar.

\section{REFERÊNCIAS}

3 TEENS kill 4 - tell me something good. Música: Doug Bressler, Brian Butterick, William Gerstel, Julie Hair, Jesse Hultberg, David Wojnarowicz. 2008. 4min. Disponível em: <https://www.youtube.com/watch?v=PkVY9zRkpJ8>. Acesso em: 15 de agosto de 2018.

A FIRE in my belly (full version). Direção: David Wojnarowicz. 2010. 20min., color. Disponível em: <https://www.youtube.com/watch?v=gHRCwQeKCuo>. Acesso em: 15 de agosto de 2018.

BEN Neill - Mutantrumpet Demo. Intérprete: Ben Neill. 2015. 4 min., son., color. Disponível em: <https://www.youtube.com/watch?v=umBVBu6nFbl>. Acesso em: 15 de agosto de 2018.

BUDICK, Ariella. The virtuosic rage of David Wojnarowicz. Financial Times, 2018. Disponivel em: <https://www.ft.com/content/f1231e42-8a66-11e8-affdda9960227309>. Acesso em: 15 de agosto de 2018. 
BÜRGER, Peter. Teoria da vanguarda. Lisboa: Vega, 1993.

CARR, Cynthia. Fire in the belly: the life and times of David Wojnarowicz. (Ebook). Nova York: Bloomsbury USA, 2012.

DOYLE, Jennifer. The transformative nature of David Wojnarowicz's ITSOFOMO. Kcet, 2013. Disponível em: <https://www.kcet.org/shows/artbound/thetransformative-nature-of-david-wojnarowiczs-itsofomo>. Acesso em: 15 de agosto de 2018.

DUBOIS, Philippe. Cinema, vídeo, Godard. São Paulo: Cosac Naify, 2004.

HUYSSEN, Andreas. Present pasts: urban palimpsests and the politics of memory. Stanford: Stanford University Press, 2003.

KAPROW, Allan. Essays on the blurring of art and life. Londres: University of California Press, 1993.

MACHADO, Arlindo. Apresentação. In: DUBOIS, Philippe. Cinema, video, Godard. São Paulo: Cosac Naify, 2004. p. 11-20.

Museo Reina Sofia. 2008. Arthur Rimbaud in New York. Museo Reina Sofia.

Disponível em: <http://www.museoreinasofia.es/en/collection/artwork/arthurrimbaud-new-york-8>. Acesso em: 15 de agosto de 2018.

MUSTO, David F.; EPSTEIN, Anne. AIDS: acquired immune deficiency syndrome. In JACKSON, Kenneth T. New York Historical Society: the encyclopedia of New York City. (E-book). New Haven: Yale University Press, 2010.

RANCIÈRE, Jacques. A política da arte. Urdimento, Florianópolis, v. 1, n. 15, p. 4559, out. 2010.

REES, A. L. A history of experimental film and video. Londres: BFI, 2011.

The Kitchen. About. The Kitchen, 2018. Disponível em: <http://thekitchen.org/about>. Acesso em: 15 de agosto de 2018.

Visual Aids. Art. Aids. Action. Visual Aids. Disponível em: <http://visualaids.org/about>. Acesso em: 15 de agosto de 2018.

David Wojnarowicz. Visual Aids. Disponível em:

<http://visualaids.org/artists/detail/david-wojnarowicz>. Acesso em: 15 de agosto de 2018.

Wright Auctions. 2016. 175: David Wojnarowicz, untitled. Wright. Disponível em: <https://www. wright20.com/auctions/2016/02/art-design/175>. Acesso em: 15 de agosto de 2018. 